\title{
Ocular manifestations among the professional computer workers attending the out patient department of Bangabandhu Sheikh Mujib Medical University : a cross sectional study
}

\author{
Nusaffarin Khan, Md Sharfuddin Ahmed, Syed Abdul Wadud, Md Showkat Kabir, Mohammed \\ Moinul Hoque, Nirupam Chowdhury, Md Golam Faruk Hossain, Shaila Rahman
}

\section{Article Info \\ Bangladesh Laser \& Cell Surgery Institute \& Hospital, Badda, Dhaka (NK), Department of Community Ophthalmology, BSMMU, Dhaka, (MSA, MSK, MMH, NC, MGFH, SR), Department of Ophthalmology, BSMMU, Dhaka (SAW) \\ For Correspondence: \\ Nusaffarin Khan \\ Email: rawnakj16@gmail.com \\ Received: \\ Accepted: \\ Available Online: \\ 10 March 2021 \\ 17 June 2021 \\ 30 November 2021 \\ ISSN: 2224-7750 (Online) \\ 2074-2908 (Print) \\ DOI: https://doi.org/10.3329/bsmmuj.v14i3.56595}

Keywords: Computer, Computer vision syndrome, Adults, Ocular Problems.

Cite this article:

Khan N, Ahmed MS, Wadus SA, Kabir MS, Hoque MM, Chowdhury N, Hossain MGF, Rahman S. Ocular manifestations among the professional computer workers attending the outpatient department of Bangabandhu Sheikh Mujib Medical University : a cross sectional study. Bangabandhu Sheikh Mujib Med Univ J. 2021; 14(3): 31-37.

\section{Copyright:}

The copyright of this article is retained by the author(s) [Atribution CC-By 4.0]

\section{Available at:}

www.banglajol.info

A Journal of Bangabandhu Sheikh Mujib Medical University, Dhaka, Bangladesh

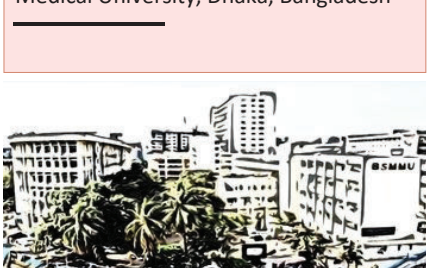

\section{Abstract}

The computer vision syndrome has become a burning issue in this modern world with the advancement of the technology and its wide use. This study was planned to determine the prevalence of computer vision syndrome among professional computer workers as well as it's associated risk factors. The cross-sectional study was conducted in the Departments of Community Ophthalmology and Ophthalmology, Bangabandhu Sheikh Mujib Medical University (BSMMU), Dhaka from September 2017 to February 2020. The professionals using computer on an average 4 hours per day for a duration of at least 1 year attending out patient department for having treatment for their ocular problems were the study population. A total of 77 such subjects were consecutively included in the study. In this present study, the prevalence of computer vision syndrome (CVS) was $46.8 \%$. The present study demonstrated that middle class and upper-middle class professionals were more likely to be associated with CVS than the lower-middle class computer professionals with risk of developing CVS in former cohort was observed to be almost 3-fold (95\% CI=1.1-7.5) higher than that in the latter cohort $(\mathrm{p}=0.027)$. The duration of working on computer predisposes the development of CVS with mean duration of working was on an average 1.2 years higher in subjects with CVS than that in subjects without CVS. Subjects who maintained their level of personal computer(PC) at or above their eye level (while working on computer) were more prone to develop CVS with odds of developing the condition in them being 3.6(95\% CI = 1.3-9.7) times higher than the subjects who maintained the level of PC below their eye level $(p=0.010)$. Glare display also emerged as significant predictor of CVS with odds having the condition being $9.8(95 \% \mathrm{CI}=$ 1.1-88.6) times higher than that with PCs without glare display $(\mathrm{p}=0.016)$. Seating posture at computer also have its impact on the development of CVS. Computer workers with inappropriate seating posture are more often associated with the development CVS. The study concluded that over one-quarter of the computer professionals suffer from computer vision syndrome (CVS). The predominant symptoms of CVS are eye strain, irritation of eye, blurred vision and headache. The factors that contribute to the development of CVS are middle class and upper-middle class professionals, prolonged working exposure to computer, level of PC at or above the eye level of the workers, glare display on the screen and inappropriate seating posture.

\section{Introduction}

With the advent of modern technology, the use of computer devices and gadgets has become necessary in every aspect of life. They are not only being used at work places, offices, academic institutions but their usage has also become very much common even at recreational places and homes. ${ }^{1-4}$ Globally, personal computers are one of the commonest office tools. Almost all institutions, colleges, universities and homes today are using computers regularly. ${ }^{5-8}$ Using computers has become a $21^{\text {st }}$ century necessity but use of computer is not completely 
safe to health. ${ }^{2}$ Numerous studies have already reported a lot of health hazards, particularly eye-related health hazards leading to loss of efficiency of the computer workers and productivity of the sectors concerned.

Prevalence of computer vision syndrome ranges between $64 \%$ to $90 \%$ among computer users. ${ }^{3}$ It has been calculated that almost 60 million people suffer from CVS globally and approximately one million new cases occur each year. ${ }^{1}$

Prolong use of computers in the workplace has brought about the development of a number of health problems. Those who work at a computer report a high level of job-related complaints and symptoms, including ocular discomfort, muscular strain and stress. The level of discomfort appears because of increase with the amount of computer use. Visual discomfort and related symptoms occurring in computer workers are growing health problem. ${ }^{3}$ Working with computers causing visually and physically fatigue which may result in lowered productivity, increased error rate and reduced job satisfaction. So, Steps should be taken to reduce the potential for development of stress and related ocular and physical discomfort at the workplace. ${ }^{10}$

South Asian region has undergone rapid socioeconomic and technological development for past few decades. So, prolonged use of computers at the workplace has brought us the development of a number of health concerns. ${ }^{4}$

The presence of even minor vision problems can often significantly affect computer worker's comfort and performance at a computer. Uncorrected or under corrected farsightedness, astigmatism, presbyopia and binocular vision (eye coordination and eye focusing) problems can be major contributing factors to computer related eye stress. ${ }^{1}$ The level of discomfort appears to increase with the amount of use of computer.

Since CVS is a growing health issue which is significantly reducing the quality of life and productivity at work place, the present study will help the public health professionals and the stake-holders to plan and take measures to reduce it. It will also help to create awareness regarding risk factors associated with Computers. Computer Vision Syndrome (CVS) is defined as a complex of eye and vision problems related to the activities which stress the near vision and which are experienced in relation to or during the use of computers. $^{2}$

Clinical manifestations of CVS: The symptoms of CVS are divided broadly into four categories-

1. Asthenopic- eye strain, tired eyes, sore eyes,

2. Ocular surface related - watering, irritation, dry eyes
3. Visual - blurred vision, slowness of focus change, double vision and

4. Extraocular - neck pain, back ache, shoulder pain. ${ }^{4}$

Factors causing to CVS are generally depend on - poor sitting position, improper viewing distances, improper viewing angle, ocular diseases, medical diseases, ageing and environment, poor resolution, poor contrast, glare of the display, poor lighting which is associated with VDT. ${ }^{6}$

The focusing systems of human eyes are not for electronically generated characters on the Video Display Terminal. It responds perfectly to the images that have well defined edges with good background contrast, example solid black letters on white background. The image that produced on a VDT consist of thousands of pixel (bright spot) and horizontal lines(rasters) which is bright at its center and with decreasing brightness towards its outer edge. ${ }^{7}$ The eyes cannot remain focused on the pixel-generated images on a computer screen. So the eyes focus and refocus thousands of times each day while viewing the screen. ${ }^{8}$ When eyes will relax on to a focus behind the screen, this point is called the resting point of accommodation (RPA) or dark focus. ${ }^{7}$ Eyes are constantly relaxing to RPA and straining to refocus on to the computer screen. The constant changing of focusing by the ciliary body creates fatigue to the eye and causes accommodative symptoms. ${ }^{8}$ Prolong VDT usage causes diminished power of accommodation and removal of the near point of convergence causing deviation of eye for near vision. ${ }^{9}$

\section{Methods}

A analytic cross sectional study done on 18- 38 years, professionals using computer on an average 4 hours per day for a duration of at least 1 year for having ocular problems were the study population. The study populations were further refined by employing following enrollment criteria. After obtaining permission from institutional review board (IRB), seventy seven patients (77) were examined in department of community ophthalmology and department of ophthalmology, Bangabandhu Sheikh Mujib Medical University (BSMMU), Dhaka during period of time September 2017 to February 2020. A Semi-structured questionnaire / data collection sheet was designed according to the objective of the study with clinical examination form. The questionnaire was validated by pre testing on 5 patients who was admitted in eye ward of BSMMU. The purposive sampling technique was applied to collect the sample from the study population. 


\section{Data collection procedure:}

Patients attending at Out Patient Department of Ophthalmology and Community Ophthalmology, Bangabandhu Sheikh Mujib Medical University. The written informed consent was obtained from all participants before enrollment in the study at the time of first screening. The sampling technique was applied to collect sample from the study population, as per inclusion and exclusion criteria. The complete clinical evaluation including history, physical examination, relevant ocular examinations (The best corrected visual acuity (BCVA), Tear film break up time, Schirmer`s test) and fundus examination was done in the Ophthalmology department, Bangabandhu Sheikh Mujib Medical University. Any pathology detected on fundoscopic examination was mentioned in data sheet. The subjects who needed further treatment were referred to the Community Ophthalmology Department of BSMMU. All findings were recorded in the data collection sheet.

\section{Statistical analysis:}

Data were processed and analyzed using SPSS, version 25.0 for Windows. The results were presented in tables and figures.

\section{Results}

The present study intended to find the prevalence of Computer vision syndrome (CVS) and its determinants included of total of 77 subjects based on predefined eligibility criteria. Of the 36(46.8\%) had CVS and the rest 41(53.2\%) did not have CVS.

Age distribution shows that mean age of the patients was 30.9 years and the youngest and the oldest patients being 21 and 38 years old respectively. A male predominance was observed in the series with male to female ratio being roughly 4:1 (Table I).

Majority of the patients was urban residents (94.8\%) and used to work on computer at office. Nearly $90 \%$ of the

\begin{tabular}{|l|c|c|}
\hline \multicolumn{3}{|c|}{ Table-I } \\
\hline \multicolumn{3}{|c|}{ Age, sex distribution of patients $(\mathbf{N}=77)$} \\
\hline Age and sex & Frequency & Percentage \\
\hline Age $^{*}$ (years) & -- & -- \\
\hline$\leq 30$ & 29 & 37.7 \\
\hline$>30$ & 48 & 62.3 \\
\hline Sex & & 77.9 \\
\hline Male & 60 & 22.1 \\
\hline Female & 17 & \\
\hline
\end{tabular}

*Mean age $=30.9 \pm 4.6$ years; range: $>18-38$ years. selected study subjects belonged to lower middle class and middle-class family.

The profile of working on computer is presented in table II. The mean duration of working on computer was $7.1 \pm 3$ years with shortest and longest durations being 2 and 12 years, while the average working hours per day was $8.9 \pm 1.9$ hours. More than $70 \%$ of the computer professionals maintained $<a$ forearm distance between their eyes and the computer screen. Approximately 55\% of the cases adjusted top of the computer screen below their eye levels, 33.8\% at the same level with their eyes and $11.7 \%$ above the level of the eyes. According to their report, seating posture seemed to inappropriate $35 \%$ cases and appropriate in $65 \%$ cases. Nearly half $(48.1 \%)$ of the professionals reported using eye-glasses while working on computer, $7.8 \%$ saw glare on the display and $3.9 \%$ used antiglare. None but only $1(1.3 \%)$ case had systemic disease.

Eye strain was the predominant $(80 \%)$ asthenopic complain followed by red eye (26\%) and eye fatigue $(15.6 \%)$. In terms of

\begin{tabular}{|l|c|c|}
\hline \multicolumn{3}{|c|}{ Table-II } \\
Distribution of patients by their profile of working on \\
computer (N = 77) \\
\hline Profile of working on computer & Frequency & $\begin{array}{c}\text { Mean } \pm \text { SD } \\
\text { (range) }\end{array}$ \\
\hline Years of working on computer (years) & -- & $7.1 \pm 3.0(2-12)$ \\
\hline Working hours on computer per day & -- & $8.9 \pm 1.9(1-10)$ \\
\hline Distance of the screen from the eyes & & - \\
\hline < a forearm distance & $54(70.1)$ & -- \\
\hline$\geq$ a forearm distance & $23(29.9)$ & - \\
\hline Level of top of the computer screen & & -- \\
\hline Above the level of the eyes & $9(11.7)$ & -- \\
\hline At the level of eyes & $26(33.8)$ & -- \\
\hline Below the level of the eyes & $42(54.5)$ & - \\
\hline Seating position & & - \\
\hline Appropriate & $27(35.1)$ & -- \\
\hline Inappropriate & $50(64.9)$ & -- \\
\hline $\begin{array}{l}\text { Using eye glasses while working } \\
\text { on computer }\end{array}$ & $37(48.1)$ & -- \\
\hline Glare on the display & $6(7.8)$ & - \\
\hline Using antiglare & $3(3.9)$ & - \\
\hline
\end{tabular}

ocular surface related symptoms, about two-thirds $(66.2 \%)$ had irritation, $58.4 \%$ watering and $42.9 \%$ dry eye. The cardinal visual complain was blurred vision $(68.8 \%)$. Slowness of focus change was rarely encountered. Change in colour perception and diminished power of accommodation were even rare. Extraocular 
manifestations- headache was the prime manifestation $(54.5 \%)$, followed by neck-pain (39\%), backache $(16.9 \%)$ and shoulder pain (9.1\%). Below table shows patents affected with asthenopic symptoms (Figure-1).

The Schirmer's test revealed that 36(46.8\%) patients had dry eye (Schirmer's Test result $<15 \mathrm{~mm}$ ), while tear film break-up time

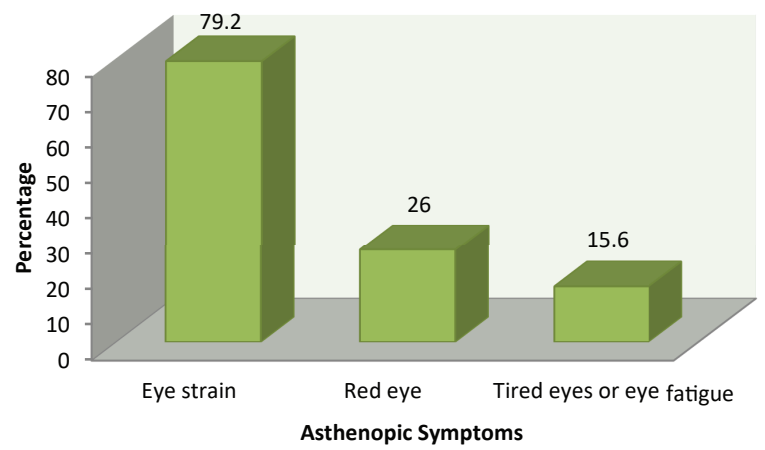

Figure-1: Distribution of the asthenopic symptoms in professional computer workers.

(TBUT) demonstrated that 41(53.3\%) patients had dry eye (TBUT $<10$ seconds). Majority $(81.8 \%)$ of the patients had best corrected visual acuity (BCVA) 6/6, 14.3\% had BCVA 6/9 and 3.9\% 6/12 (Table III).

Based on the criteria set for defining computer vision syndrome (CVS) for the present study, a total 36(46.8\%) subjects had CVS. Table IV shows that association between demographic characteristics and CVS. None of the demographic characteristics (shown in the table) but socioeconomic status was found to be associated CVS. Middle class and upper-middle class professionals were more likely to be associated with CVS than do their lower-middle class

\begin{tabular}{|c|c|c|}
\hline \multicolumn{3}{|c|}{ Table-III } \\
\hline \multicolumn{3}{|c|}{$\begin{array}{c}\text { Distribution of patients by their ocular examination } \\
\text { findings }(N=77)\end{array}$} \\
\hline Ocular examination findings & $\begin{array}{l}\text { Frequency } \\
\qquad(\%)\end{array}$ & $\begin{array}{l}\text { Mean } \pm \text { SD } \\
\quad \text { (range) }\end{array}$ \\
\hline \multicolumn{3}{|l|}{ Schirmer's Test result (mm) } \\
\hline$<5$ & $2(2.6)$ & \\
\hline $5-10$ & $29(37.7)$ & \\
\hline $10-15$ & $5(6.5)$ & $13.3 \pm 7.9(3-30)$ \\
\hline$\geq 15$ & $41(53.2)$ & \\
\hline \multicolumn{3}{|c|}{ Tear-film break-up time (TBUT) (sec) } \\
\hline$<10$ & $36(46.7)$ & -- \\
\hline$\geq 10$ & $41(53.3)$ & - \\
\hline \multicolumn{3}{|c|}{ Best corrected visual acuity (BCVA) } \\
\hline $6 / 6$ & $63(81.8)$ & -- \\
\hline $6 / 9$ & $11(14.3)$ & -- \\
\hline $6 / 12$ & $3(3.9)$ & - \\
\hline CVS & & -- \\
\hline Present & $36(46.8)$ & -- \\
\hline Absent & $41(53.2)$ & -- \\
\hline
\end{tabular}

counterparts $(p=0.027)$. The risk of developing CVS in middle class and upper-middle class computer workers was observed to be almost 3-fold (95\% CI $=1.1-7.5)$ higher than that in the lower middle-class workers (Table-IV).

Although there was no significant difference between subjects with and without CVS in terms of years of working on computer and average working hours per day, the mean years

Table-IV

Association between demographic characteristics and CVS

\begin{tabular}{|c|c|c|c|c|c|}
\hline \multirow{2}{*}{\multicolumn{2}{|c|}{ Demographic characteristics* }} & \multicolumn{2}{|c|}{ CVS } & \multirow{3}{*}{$\begin{array}{c}\mathrm{p} \text {-value } \\
0.601\end{array}$} & \multirow{3}{*}{$\begin{array}{c}\text { Odds Ratio } \\
(95 \% \text { CI of OR) } \\
1.3(0.6-3.3)\end{array}$} \\
\hline & & \multirow{2}{*}{$\frac{\text { Present }(n=36)}{12(41.4)}$} & \multirow{2}{*}{$\begin{array}{c}\text { Absent }(\mathrm{n}=41) \\
17(35.4)\end{array}$} & & \\
\hline Age (years) & $\leq 30$ & & & & \\
\hline & $>30$ & $17(58.6)$ & $31(64.6)$ & & \\
\hline \multirow[t]{2}{*}{ Sex } & Male & $21(72.4)$ & $39(81.3)$ & 0.404 & $0.6(0.2-1.8)$ \\
\hline & Female & $8(27.6)$ & $9(18.8)$ & & \\
\hline \multirow[t]{2}{*}{ Residence } & Rural & $2(6.9)$ & $2(4.2)$ & 0.601 & $1.7(0.2-12.8)$ \\
\hline & Urban & $27(93.1)$ & $46(95.8)$ & & \\
\hline \multirow[t]{2}{*}{ Occupation } & Office work on computer & $26(89.7)$ & $42(87.5)$ & 0.775 & $1.2(0.3-5.4)$ \\
\hline & Others & $3(10.3)$ & $6(12.5)$ & & \\
\hline \multirow[t]{2}{*}{ Socioeconomic status } & Middle \& upper middle class & $19(65.5)$ & $19(39.6)$ & 0.027 & $2.9(1.1-7.5)$ \\
\hline & Lower middle & $10(34.5)$ & $29(60.4)$ & & \\
\hline
\end{tabular}

Figures in the parentheses indicate corresponding $\%$; ${ }^{*}$ Chi-squared Test $\left(\chi^{2}\right)$ was done to analyze the data. 
Table-V

Association between working profile on computer and CVS

\begin{tabular}{|c|c|c|c|c|}
\hline \multirow[t]{2}{*}{ Profile of working on computer* } & \multicolumn{2}{|r|}{ CVS } & \multirow[t]{2}{*}{$\mathrm{p}$-value } & \multirow{2}{*}{$\begin{array}{c}\text { Odds Ratio } \\
\text { (95\% CI of OR) }\end{array}$} \\
\hline & Present $(n=36)$ & Absent $(n=41)$ & & \\
\hline \multicolumn{5}{|l|}{ Distance screen eye } \\
\hline > a forearm distance & $19(65.5)$ & $35(72.9)$ & 0.492 & $0.7(0.3-1.9)$ \\
\hline$\leq \mathrm{a}$ forearm distance & $10(34.5)$ & $13(27.1)$ & & \\
\hline \multicolumn{5}{|l|}{ Level of PC } \\
\hline At or above the level of eye & $15(51.7)$ & $11(22.9)$ & 0.010 & $3.6(1.3-9.7)$ \\
\hline Below the level of eye & $14(48.3)$ & $37(77.1)$ & & \\
\hline \multicolumn{5}{|l|}{ Seating position } \\
\hline Appropriate & $13(44.8)$ & $14(29.2)$ & 0.163 & $1.9(0.8-5.2)$ \\
\hline Inappropriate & $16(55.2)$ & $34(70.8)$ & & \\
\hline \multicolumn{5}{|l|}{ Using glass } \\
\hline Yes & $14(48.3)$ & $23(47.9)$ & 0.976 & $1.0(0.4-2.6)$ \\
\hline No & $15(51.7)$ & $25(52.1)$ & & \\
\hline \multicolumn{5}{|l|}{ Glare display } \\
\hline Yes & $5(17.2)$ & $1(2.1)$ & 0.016 & $9.8(1.1-88.6)$ \\
\hline No & $24(82.8)$ & $47(97.9)$ & & \\
\hline \multicolumn{5}{|l|}{ Using antiglare } \\
\hline Yes & $1(3.4)$ & $2(4.2)$ & 0.875 & $0.8(0.1-9.4)$ \\
\hline No & $28(96.6)$ & $46(95.8)$ & & \\
\hline
\end{tabular}

Figures in the parentheses indicate corresponding \%; ${ }^{*}$ Chi-squared Test $\left(\chi^{2}\right)$ was done to analyze the data.

of working on computer was considerably higher in subjects with CVS than that in subjects without CVS (7.6 \pm 2.9 vs. $6.4 \pm$ $3.1, \mathrm{p}=0.108)$.

Table $\mathrm{V}$ shows that association between profile of working on computer and CVS. Level of PC at or above the eye level of the subjects (while working on computer) emerged as significant determinant of CVS than does the level of PC below the eye level with risk having the condition in the former cohort was 3.6(95\% CI $=1.3-9.7)$ times higher than the that in the latter cohort $(\mathrm{p}=0.010)$. Glare display also act as significant determinant of CVS with odds having the condition being 9.8(95\% CI $=1.1-88.6)$ times higher than that with PCs without glare display $(\mathrm{p}=0.016)$. Appropriate seating posture at computer also influence the development of CVS, although the difference was not statistically significant $(p=0.163)$.

\section{Discussions}

In the present study, the prevalence of computer vision syndrome (CVS) was found $46.8 \%$. This is quite low in comparison to other similar studies conducted around the world. Previous studies on CVS from Sri Lanka (Ranganatha SC, \& Jailkhani S.,2019), Malaysia (Akinbinu, TR \& Mashalla,2013) and Nigeria (Rahman, ZA \& Sanip,2011) have demonstrated higher prevalence of the condition $(86.2 \%$, $68.1 \%, 74.0 \%$ respectively). ${ }^{11,12,13}$.Noreen $\mathrm{K}$ et al.,(2016) demonstrated that two-thirds $(67.2 \%)$ of the undergraduate medical students had at least one of the symptoms (headache, eye fatigue, burning sensation, eye irritation, neck shoulder pain) of CVS. ${ }^{17}$ The prevalence of computer vision syndrome was found to be higher $(70 \%)$ in Dessie A. et al. (2108) study. ${ }^{15}$ Ranganatha SC, Jailkhani S.,(2019)in a very recent cross-sectional study done on Computer Science students in Bengaluru showed an even higher prevalence of CVS $(86.7 \%)$ with commonest symptoms of CVS being headache $(83.5 \%)$ followed by eye strain(64.6\%). The comparatively high prevalence of CVS in other studies might be due to different criteria set in different studies for defining CVS. They considered CVS if the study subjects experiencing at least one of the ocular symptoms like redness of eyes, burning sensation of eyes, eye strain, blurred vision, dry eye, headache, backache and neck or shoulder pain and used computers in one month preceding the date of the study ${ }^{11}$. Noreen et al., (2016) also used the same criteria. This seems to be a very lax criteria for defining CVS, because syndrome is a constellation of a group 
of symptoms and as such only one criterion cannot be sufficient to qualify a syndrome.17

In the present study, predominant ocular manifestation was eye strain (80\%), blurred vision $(68.8 \%)$, eye irritation $(66.2 \%)$, watering of eye $(58.4 \%)$ and headache $(54.5 \%)$. Megwas AU, Aguboshim RC (2009) reported that headache (41.8\%), pain (31.6 \%) and eye strain (26.7 \%) were the most prevalent visual symptoms among VDT users. ${ }^{17}$ Headache was the most commonly reported symptom in computer users in several other similar studies (Mashalla YJ, 2012; Reddy et al., 2013, Shrestha et al., 2011). ${ }^{12,18,19}$. Noreen et al., (2016) demonstrated that ocular symptoms in computer professionals to range from eye irritation (48\%), burning sensation (33\%), eye fatigue $(15 \%) .{ }^{16,20}$. Extraocular manifestations included neck shoulder pain $(21.8 \%)$ to headache $(38 \%)$ problems. ${ }^{16,20 .}$

As factors contributing to the development of CVS were analyzed, the present study demonstrated that middle class and upper-middle class professionals were more likely to be associated with CVS with the risk of developing CVS, almost 3-fold (95\% CI = $1.1-7.5)$ higher than that in the latter class workers ( $p=0.027)$. Ranasinghe et al., (2016) found prevalence of CVS to be significantly greater in older professionals with mean age of those with CVS being $31.2 \pm 7.8$ years and those without CVS being $29.9 \pm 8.6$ years respectively.

Subjects who maintained their level of PC at or above their eye level (while working on computer) were more prone to develop CVS with odds of developing the condition in them being 3.6(95\% CI = 1.3-9.7) times higher than the subjects who maintained the level of PC below their eye level $(p=0.010)$. Glare display also emerged as significant predictor of CVS with odds of having the condition being almost 10(95\% CI = 1.1-88.6)- times higher than that with PCs without glare display $(p=0.016)$. Seating posture at computer also have its impact on the development of CVS. Computer workers with inappropriate seating posture are more often associated with CVS. Another recent study demonstrated that CVS significantly associated with sitting arrangements (chair support to lower back, keeping computer screen at eye level, monitor can be tilted/raised/lowered and screen having glare filter) and average hours of working per day on computer, which are consistent with findings of the present study. ${ }^{11}$

\section{Conclusions}

It is a multidirectional approach due to the variety of complaints among computer users. From the findings of present study, the predominant symptoms of CVS are eye strain, irritation of eye, blurred vision and headache. The socio-demographic factors, extended years of working on computer, higher daily computer usage, level of PC at or above the eye level of the workers. Not using a VDT filter, glare display, Inappropriate seating posture also plays significant role in the predisposition of CVS. Regular follow-up, ocular treatment, Improving awareness, adjustment of the user's work station, knowledge of ergonomics and proper management support at office will be reducing the incidence of CVS in future.

\section{References}

1. Sen A, Richardson S. A study of computer-related upper limb discomfort and computer vision syndrome. Journal of human ergology. 2007;36(2):45-50.

2. American Optometric Association. Guide to the Clinical Aspects of Computer Vision Syndrome; American Optometric Association: St. Louis, MO, USA. 1995.

3. Hayes JR, Sheedy JE, Stelmack JA, Heaney CA. Computer use, symptoms, and quality of life. Optometry and vision science. 2007;84(8):E738-55.

4. Blehm C, Vishnu S, Khattak A, Mitra S, Yee RW. Computer vision syndrome: a review. Survey of ophthalmology. 2005 ;50(3):253-62.

5. Logaraj M, Madhupriya V, Hegde SK. Computer vision syndrome and associated factors among medical and engineering students in Chennai. Annals of medical and health sciences research. 2014;4(2):179-85.

6. Thomson WD. Eye problems and visual display terminals - the facts and the fallacies. Ophthalmic and physiological optics. 1998 Mar 1;18(2):111-9.

7. Wimalasundera S. Computer vision syndrome. Galle Medical Journal. 2009 ;11(1): 25-29.

8. Assefa NL, Weldemichael DZ, Alemu HW, Anbesse DH. Prevalence and associated factors of computer vision syndrome among bank workers in Gondar City, northwest Ethiopia, 2015. Clinical Optometry. 2017;9:67.

9. Bali J, Navin N, Thakur BR. Computer vision syndrome: a study of the knowledge, attitudes and practices in Indian ophthalmologists. Indian journal of ophthalmology. 2007 ;55(4):289.

10. Arumugam S, Kumar K, Subramani R, Kumar S. Prevalence of computer vision syndrome among information technology professionals working in Chennai. World Journal of Medical Sciences. 2014;11(3):312-4.

11. Ranganatha SC, Jailkhani S. Prevalence and associated risk factors of computer vision syndrome among the computer science students of an engineering college of Bengaluru-a cross-sectional study. Galore Int J Health Sci Res. 2019; 4(3): 10-5. 
12. Mashalla YJ. Impact of computer technology on health: Computer Vision Syndrome (CVS). Medical Practice and Reviews. 2014;5(3):20-30.

13. Rahman ZA, Sanip S. Computer user: demographic and computer related factors that predispose user to get computer vision syndrome. Int J Bus Humanit Technol. 2011;1(2):84-91.

14. Ranasinghe $\mathrm{P}$, Wathurapatha WS, Perera YS, Lamabadusuriya DA, Kulatunga S, Jayawardana $\mathrm{N}$ et al. Computer vision syndrome among computer office workers in a developing country: an evaluation of prevalence and risk factors. BMC research notes. 2016 ;9(1):150.

15. Dessie A, Adane F, Nega A, Wami SD, Chercos DH. Computer vision syndrome and associated factors among computer users in debre tabor town, northwest Ethiopia. Journal of environmental and public health. 2018 ; 2018 : 4107590
16. Noreen K, Batool Z, Fatima T, Zamir T. Prevalence of computer vision syndrome and its associated risk factors among under graduate medical students of urban karachi. Pakistan Journal of Ophthalmology. 2016;32(3): 140-146.

17. Megwas AU, Aguboshim RC. Visual Symptoms Among Non-presbyopic Video Display Tterminal (VDT) Operators In Owerri, Nigeria. Journal of the Nigerian Optometric Association. 2009;15:33-6.

18. Reddy SC, Low CK, Lim YP, Low LL, Mardina F, Nursaleha MP. Computer vision syndrome: a study of knowledge and practices in university students. Nepalese journal of Ophthalmology. 2013 ;5(2):161-8.

19. Shrestha GS, Mohamed FN, Shah DN. Visual problems among video display terminal (VDT) users in Nepal. Journal of Optometry. $2011 ; 4(2): 56-62$.

20. Sheedy J. Doctor Ergo and CVS Doctors: meeting the eye care needs of computer users. J Behav Optom. 2000; 11:123-126 